\title{
Conceptualizing smart service systems
}

\author{
Daniel Beverungen $^{1} \cdot$ Oliver Müller $^{2} \cdot{\text { Martin } \text { Matzner }^{3}(\mathbb{D} \cdot \mathrm{Jan} \text { Mendling }}^{4}$ • \\ Jan vom Brocke 5
}

Received: 31 March 2017 / Accepted: 4 October 2017 / Published online: 16 November 2017

(C) The Author(s) 2017. This article is an open access publication

\begin{abstract}
Recent years have seen the emergence of physical products that are digitally networked with other products and with information systems to enable complex business scenarios in manufacturing, mobility, or healthcare. These "smart products", which enable the co-creation of "smart service" that is based on monitoring, optimization, remote control, and autonomous adaptation of products, profoundly transform
\end{abstract}

Responsible Editors: Anne Moen and Rainer Alt

Martin Matzner

martin.matzner@fau.de

Daniel Beverungen

daniel.beverungen@upb.de

Oliver Müller

oliver.mueller@itu.dk

Jan Mendling

jan.mendling@wu.ac.at

Jan vom Brocke

jan.vom.brocke@uni.li

1 Department of Information Systems, Paderborn University, Warburger Strasse 100, 33098 Paderborn, Germany

2 Department of Information Management, IT University of Copenhagen,

Rued Langgaards Vej 7, DK-2300 Copenhagen S, Denmark

3 Instiute of Information Systems, University of Erlangen-Nürnberg, Lange Gasse 20, 90491 Nuremberg, Germany

4 Department of Information Systems and Operations, Vienna University of Economics and Business, Welthandelsplatz 1, 1020 Vienna, Austria

5 Hilti Chair of Business Process Management, University of Liechtenstein,

Fürst-Franz-Josef-Strasse, 9490 Vaduz, Liechtenstein service systems into what we call "smart service systems". In a multi-method study that includes conceptual research and qualitative data from in-depth interviews, we conceptualize "smart service" and "smart service systems" based on using smart products as boundary objects that integrate service consumers' and service providers' resources and activities. Smart products allow both actors to retrieve and to analyze aggregated field evidence and to adapt service systems based on contextual data. We discuss the implications that the introduction of smart service systems have for foundational concepts of service science and conclude that smart service systems are characterized by technology-mediated, continuous, and routinized interactions.

Keywords Smart service $\cdot$ Smart products $\cdot$ Internet of things $\cdot$ Service science $\cdot$ Boundary object

JEL classification L $8 \cdot \mathrm{O} 3$

\section{Introduction}

Imagine that (in a couple of years) you own a smart washing machine. Of course, your machine's primary purpose is to do the laundry, but it is also equipped with various sensors that determine the weight of your laundry, judge the quality of the water, and identify the properties (e.g., material, color, dirtiness) of your laundry. Based on these data, the machine autonomously applies just the right amounts of washing powder, water, and electricity; therefore, reducing its environmental footprint and saving money. The company that built your machine can access your data remotely and compare them with data of thousands of other washing machines in the installed base so it can compare your washing machine's efficiency and effectiveness with the performance of other machines used in 
comparable settings. Based on the results, the company can adjust the inference engine inside your machine remotely, fine-tuning and optimizing its autonomous functions. This machine also offers a dry-cleaning service that is tailored to your own idiosyncratic needs, perhaps increasing your willingness-to-pay for the machine.

In this way, smart service systems bring a customer's and provider's perspective on value creation with a smart product together. Also going by names like smart devices, smart objects, and cyber-physical systems, embedding hardware and software systems into physical goods that can connect digitally to other products and information systems is a powerful trend in many industries. Smart products use sensors to obtain contextual data, exchange data with other actors, store and process data locally, make autonomous decisions, and act physically by means of actuators (Acatech 2011). In this way, previously isolated and passive products join the digitally networked world as actors in their own right.

Application scenarios that benefit from the proliferation of smart products are present in many industries, including transport and logistics, manufacturing, energy supply, healthcare, and industries related to living and working in smart buildings (Acatech 2011; Atzori et al. 2010) — even though what "smart" exactly means often remains unspecified (Gretzel et al. 2015). For example, in the area of smart mobility, cars are evolving from pure driving machines to intelligent dataprocessing units that obtain data on their physical surroundings (e.g., road conditions, the position and trajectory of other vehicles), connect to other intelligent devices and smart infrastructure (e.g., toll-collection systems, traffic information systems), and adapt their actions in near real-time based on the analysis of various data streams (e.g., braking after detecting a dangerous situation). Both, consumers and service providers can benefit from the new capabilities of smart products, as Virgin Atlantic IT director David Bulman explains: "The latest planes we are getting, the Boeing $787 \mathrm{~s}$, are incredibly connected. Literally every piece of that plane has an Internet connection, from the engines, to the flaps, to the landing gear. [...] If there is a problem with one of the engines we will know before it lands to make sure that we have the parts there" (Finnegan 2013).

Clearly, these developments offer tremendous opportunities. Smart products enable the design and delivery of an entirely new class of service that is built on obtaining contextual data from the field, analyzing these data, automatically making decisions and taking action. However, current research in computer science and engineering is focused on the technical aspects of smart products, including questions related to communication standards, naming and addressing of objects, authentication, privacy, and security (Atzori et al. 2010; Perera et al. 2014). This technical view neglects a much-needed re-conceptualization of how value can be co-created and captured from these technologies, as has been argued in literature that has advocated collaboration between complementary research communities (Atzori et al. 2010). For its part, the service science literature is often focused on how value is co-created and captured (Lusch et al. 2008; Maglio et al. 2009; Vargo and Lusch 2004a, 2008a), without recognizing the transformative potential smart products offer. In particular, we argue that the introduction of smart products transforms service systems - framed as "a configuration of people, technologies, and other resources that interact with other service systems to create mutual value" (Maglio et al. 2009, p. 395) - into smart service systems. Related research has emphasized the self-reconfiguration (Barile and Polese 2010), humancentered (Demirkan et al. 2015a), context-aware (Massink et al. 2010), or self-* (National Science Foundation 2014) properties of smart service systems, but without proposing an overarching conceptual framework for how these properties interact.

The objective of this paper is to conceptualize the "smart service system" as a theoretical lens through which digital value co-creation by service consumers and service providers can be understood, analyzed, and designed. Central to our conceptualization is that, in smart service systems, smart products take the role of boundary objects that digitally mediate the interactions of service providers and service consumers and enable the co-creation of individualized value propositions. With this framework, we integrate distinct strands of research, including the nature and properties of boundary objects (Star and Griesemer 1989; Star 2010; Carlile 2002), co-creation of value in service systems (Lovelock and Gummesson 2004; Vargo and Lusch 2008a; Maglio et al. 2006; Lusch and Vargo 2006; Vargo and Lusch 2004b; Maglio et al. 2009), properties of smart products in the context of the Internet of Things (Atzori et al. 2010; Allmendinger and Lombreglia 2005; Acatech 2011; Perera et al. 2014), and capabilities of smart devices (Porter and Heppelmann 2014). In addition to this literature review, our work is informed by in-depth interviews with informants from a variety of industries that have started introducing smart products into their service systems.

The remainder of the paper is structured as follows. Section 2, reviews the core properties of smart products and the Internet of Things and discusses their implications on conceptualizing smart service and smart service systems. Section 3, we provide an overview of the empirical cases we analyzed in order to support and enrich our conceptual arguments. Section 4, presents our conceptualization of smart service systems, which is informed by the preceding literature review and expert interviews. In Section 5, we discuss the theoretical implications of smart service systems on other constructs in service science. Section 6 concludes the paper. 


\section{Theoretical background}

\section{Smart products and the Internet of Things}

Smart products are part of an environment that is referred to as the Internet of Things (Papert and Pflaum 2017). Equipping physical products with embedded systems and networking has its roots in the fields of mechanical and electrical engineering and computer science. The advantages of this combination have been discussed in the contexts of ubiquitous computing (Weiser 1991, 1993), pervasive computing (Satyanarayanan 2001; Estrin et al. 2002), and ambient intelligence (Aarts et al. 2002). Most significant in this context is the Internet of Things (Wortmann and Flüchter 2015; Atzori et al. 2010; Perera et al. 2014) as "[t]hings having identities and virtual personalities operating in smart spaces using intelligent interfaces to connect and communicate within social, environmental, and user contexts" (EPoSS 2008, p.6). With the advent of the Internet of Things, embedded systems in physical objects became connected to a world-wide communication network, providing data to and receiving data from other devices and information systems.

A list of key features, though not constitutive or exhaustive, has been attributed to smart products (Weiser 1993; Weiser 1991; Satyanarayanan 2001; Acatech 2011; Porter and Heppelmann 2014; Allmendinger and Lombreglia 2005; Atzori et al. 2010). Among them is the unique identifier that makes a smart product addressable by other products and information systems. They "know" their location and can be localized and traced by other devices and information systems. Smart products can be connected with distributed information and other resources via standard communication protocols (Atzori et al. 2010), and with this connectivity, they can share data and functionality with other devices and information systems that might even be globally distributed. With sensors, smart products directly obtain physical data that are available in their proximity, so they become aware of their surroundings, including users and other smart products. Smart products can store in their own memory banks data that might include status data, usage data, and contextual data obtained by sensors. Bounded by "low resources in terms of both computation and energy capacity" (Atzori et al. 2010), the devices compute these data and adapt their actions accordingly, resulting in autonomous behavior that may influence other actors in the physical and/or digital spheres. With actuators, smart products can manipulate physical reality in their proximity, so they are not passive objects, but actors. Smart products have dedicated, multimodal human-machine interfaces, some of which may feature modes of user interaction other than those of classic desktop computers (e.g., based on gestures). The ideal smart product is sufficiently unobtrusive to avoid bothering a user's consciousness with its presence, blending naturally into the environment in which a user is acting (Weiser 1991, 1993; Satyanarayanan 2001). In effect, the device masks the adverse consequences of being located in a "dumb" environment by performing activities for compensation (Satyanarayanan 2001). Thus, a smart product might be detectable by a user only in the event of a malfunction while being otherwise an invisible computer.

We argue that not all of these properties must be present in each smart product. For instance, smart immobile goods (e.g., manufacturing equipment) might not require being locatable through sensors and might not include invisible computers beyond their operating systems and automation technologies. Similarly, smart consumer goods (e.g., wearables) might not need to have sophisticated actuators to change their physical appearance or data storage and computational capabilities.

\section{Smart service based on smart products}

From the point of view of service science, a research discipline that is focused on the co-creation and capture of value in the reciprocal business relationships between service customers and service providers, the term "service" is defined as "the application of specialized competences (operant resourcesknowledge and skills), through deeds, processes, and performances for the benefit of another entity or the entity itself' (Vargo and Lusch 2008a, p. 26). Therefore, service refers to the value-in-use (Vargo and Lusch 2008b; Vargo et al. 2010; Vargo and Lusch 2008a) that is co-created in interactions between service providers and service customers for their mutual benefit (Vargo and Lusch 2004a, 2008a, b). The organizational settings in which service is co-created are service systems, which are "configurations of people, technologies, and other resources that interact with other service systems to create mutual value" (Maglio et al. 2009, p.395).

A recent survey among service scientists revealed that the proliferation of IT, such as IT in the form of smart products, gives rise to an "ubiquitous, always on, always connected, smart, and global world [and] is leading to profound changes in customer experience and value co-creation; front-stage and back-stage service provision; and service organizations, networks and service ecosystems" (Ostrom et al. 2015, p.145). This perception is largely shared by leading industry experts (Demirkan et al. 2015b). Such smart service is based on two core properties of smart products: awareness and connectivity (Allmendinger and Lombreglia 2005). With these properties, smart products can provide data on how they are used back to the provider, who can use this information to offer their customers contextual and preemptive services that are based on the "hard field intelligence" the smart products provide (Allmendinger and Lombreglia 2005, p.132). This service enables providers to establish and cultivate close ties with their customers along the entire lifecycle of a smart product-from requirements analysis to disposal — and to inform their research 
and development processes. Customers are paying a price premium to be relieved of "unpleasant surprises" that threaten their businesses (Allmendinger and Lombreglia 2005, p.132), including unexpected downtimes that often cost them a great deal of money. In addition, service providers might grow their businesses by taking over adjacent activities from customers, thereby evolving from pure providers of hardware into solution-providers that optimize their product's entire lifecycle or even into service aggregators who manage the channel between customers and third-party providers of complementary services that are based on the data that is retrieved from their smart products (Allmendinger and Lombreglia 2005).

The foundational premises of service science (Vargo and Lusch 2008a, 2016; Vargo et al. 2010) suggest two major views on how smart products enable "service". First, smart products themselves can act as service-distribution mechanisms since they embody the provider's (operant) knowledge and skills, which become manifest in the product's physical appearance. Second, the foundational premise stating that all social and economic actors are resource integrators implies that smart products must be networked with other resources that are owned by either actor that participates in a service system.

From a theoretical standpoint, then, smart products' properties have various implications for conceptualizing smart service as service that relies on using smart products (Table 1).

\section{Methodology and cases}

In order to explore how the emergence of smart products transforms service and service systems, we studied five cases from different industries. For each case, we performed indepth interviews with key informants who were responsible for designing and managing service systems that involve smart products. The interviews were guided by an interview script with three sections: a brief introduction of the core properties listed in Table 1 and the request that the informant name and broadly characterize the smart products that are used or provided in his or her sphere of influence; a request that the informant describe in detail how the core properties (if applicable) manifest in the considered smart products he or she listed by explaining how particular key features of smart product apply to the smart products used in or offered by the informant's company; and a request to explain whether (and which) new functions are enabled by the smart product, to explain whether the provider's or the users current processes leveraged the functions, and to describe implications of the emergence of smart products and service with regards to their business processes and business models.

Recruitment of the interview partners relied on convenience sampling because of the novelty of smart services and smart products, a theoretical sampling that included a
Table 1 Core properties of smart products and their implications for smart service

Properties of smart products Implications for smart service

Unique Identification

Smart products become identifiable resources in service systems that can be distinguished from other resources of the same type, so data can be stored with reference to a unique product. Smart products provide an additional channel through which to design, offer, and deliver service.

Localizing

Service can be configured and delivered based on the locations of individual or groups of smart products.

Connectivity Through information technology, smart products can be integrated with resources at remote locations. Mediated by smart products' technology, service can be co-created by integrating knowledge, skills, resources, activities, and information systems that are at the disposal of different stakeholders.

Sensors

Based on contextual data, usage data, and condition data, service can be tailored to the context-sensitive surroundings in which a smart product is operated.

Storage and Computation

Smart products offer service locally and autonomously, beyond the full control of a central system. Data from single or groups of products is available for analysis in (near) real-time.

Actuators

Service can be manifested in physical locations by the actions of smart products. With remote control, external actors can have an effect on the physical manifestation of service at the customer's service system.

Interfaces

Service is co-created in local interactions between smart products and customers.

Invisible computers

Service can be offered and delivered while generating little (if any) user attention. Data in the proximity of the product can be collected without users' knowledge, which raises issues of data protection and the ethics of using data in smart service systems.

saturation condition was not feasible. The companies we investigated were selected for two reasons: their business models depend on using or providing physical goods that are currently evolving into smart products, and they large, international enterprises with a high degree of maturity and drive for innovation. In this way, we ensured that the informants were engaged in smart products to an extent that warrants an investigation. The resulting set of informants was also likely to provide us with a rich and representative view of 
smart services, as they account for matters of business, information technology, or engineering, and their responsibilities include managerial as well as analytical tasks. We were confident that the informants' complementary perspectives would allow us to investigate how smart products could take a boundary spanning role in smart service. Before conducting the interviews, we sent a two-page summary of the main interview questions to each interviewee, and each interview lasted for about an hour. All interviews were conducted by phone, tape-recorded, and transcribed. One interview was conducted in English, and the others were conducted in German and translated by the authors for the purposes of this paper.

Data analysis was conducted in a two-step process. In the first step, we applied open coding (Saldaña 2009) to identify text fragments from the interview transcripts that were potentially relevant to characterizing smart products. This process was open-ended and was not influenced by any a priori constructs. In the second step, we used focused and elaborative coding (Saldaña 2009) to identify and group the identified text fragments and relate them to our a priori categories (i.e., properties of smart products and smart service). The outcomes of the interviews were then used, in combination with the findings of the literature review to conceptualize and illustrate the properties of smart service systems (Section 3).

The first company we studied, Metallurgic Plants, Inc. (all company names in this paper are pseudonyms), offers machinery, services, and entire turnkey solutions for metallurgical plants, especially steel mills. The smart products in focus were machines used in steel factories, each equipped with automation technology and sensor networks that produce a continuous stream of measurements about the production process (e.g., temperatures, velocities) and the machine's status. These these capabilities enable Metallurgic Plants, Inc. to offer various types of smart services, such as condition monitoring, process monitoring, quality documentation, and predictive and remote maintenance. The informant at Metallurgic Plants, Inc. was the Head of Sales and Distribution of Services and the Chief Service Manager.

Automobile, Inc. is one of the best-selling makers of luxury autos in the world. We conducted two interviews, each with a unique focus. The first interview focused on smart connected cars, which assist drivers in finding their routes and parking spaces efficiently and conveniently. Connected cars can be tracked from a distance by electronic means so preventive maintenance measures can be undertaken if anomalies occur, while data can also enable remote unlocking and usage documentation. The informant was the Head of Consumer Management of the Digital Services and Digital Business Models unit.

The smart products that were the focus of the second interview at Automobile, Inc. were automated production technologies for the manufacturing of automobiles, such as robots that insert windows into cars. These machines host dozens of sensors for controlling and documenting the manufacturing processes, which enables Automobile Inc. to offer services like statistical quality control, energy consumption management, and safe human-machine cooperation. The interviewee was a mechanical engineer in the Pre-Development department.

Industrial Solutions, Inc. is a multinational conglomerate and one of Europe's largest engineering companies. The interviews focused on designing, operating, and maintaining heavy machinery (e.g., turbines) and entire smart factories. These products have most of the properties of smart products and enable various types of smart service, ranging from the virtual animation of plants and production processes over predictive maintenance to performance-contracting business models. The informant at Industrial Solutions Inc. was a Product-IT specialist.

Energy Solutions, Inc. is a multinational company that offers technology for energy grids and home appliances for energy management in buildings. The interviews focused on smart meters that are used for routing energy through the high-voltage energy grid, but additional questions on smart meters in homes extended the scope from the business-tobusiness to the business-to-consumer domain. The products Energy Solutions, Inc. offers implement all features of smart products. The interviews highlighted that the company envisions implementing even more elaborate data storage and analysis capabilities in its products in the near future in order to make local decisions that impact the routing of energy through the net. Smart meters could also be equipped with invisible computers in order to make data on energy consumption available for managing the energy grid, such that energy supply and demand can be levelled, and personalized pricing models can be established. The interviewee at Energy Solutions, Inc. is a specialist for the analysis of smart data, autonomic computing, and process automation.

\section{Conceptualization and illustration of smart service systems}

Based on the identified properties of smart products and service systems and based on the foundational premises of service science, we argue that smart products mediate interactions between service providers and service consumers in two ways: when consumers use the products' embedded functionality as a self-service, and when service providers use a smart product to connect remotely to the operations the service's consumer performs. For instance, a smart product could transmit data on its use, condition, and context back to the service provider, who analyses these data to offer additional value propositions that fit the detailed contextual situation the customer encounters. In this sense, the smart product acts 
like a boundary object - an artifact that resides at the interfaces between different fields or communities and enables cross-boundary information and knowledge transfer (Star and Griesemer 1989; Star 2010; Carlile 2002).

Against this backdrop, we define smart service and smart service systems as follows:

I. Smart service is the application of specialized competences, through deeds, processes, and performances that are enabled by smart products.

II. Smart service systems are service systems in which smart products are boundary-objects that integrate resources and activities of the involved actors for mutual benefit.

Figure 1 summarizes our conceptualization of smart service systems. The framework will be described and illustrated in detail in the following.

The co-creation of value in any service system is subject to the basic roles of service consumer and service provider. In most cases, these roles are fulfilled by two independent organizations, but sometimes a single organization can take both roles. For example a Automobile, Inc. the operation and maintenance of smart production technology for the manufacturing plants is done by internal business units. Similarly, as the Chief Service Manager at Metallurgic Plants, Inc. clarified, "as steel mills traditionally have large internal maintenance departments, our smart products first and foremost enable the customer to better operate and maintain his facilities in a self-service fashion."

In line with the service blueprinting approach (Shostack 1982; Kingman-Brundage 1989), the two roles are divided by a line of interaction and by two lines of visibility. The line of interaction separates the activities service consumers perform from those service providers perform. It delineates the value-in-use captured, the activities performed, and the resources owned by the two roles that can be taken over by actors in a smart service system. The lines of visibility separate activities and resources that are visible to other actors in a service system from those that are not, thereby determining what data and functionality can be enacted by the actors involved.

We argue that, in smart service systems, smart products take the role of boundary objects - artifacts that reside at the interfaces between roles or those between communities and facilitate the transfer of cross-boundary information and knowledge (Carlile 2002; Star and Griesemer 1989; Star 2010; Becker et al. 2013b). A boundary object has two basic properties: they are sufficiently robust to maintain a single shared identity across communities, so they can act as reference points during collaboration (Star and Griesemer 1989), and they are sufficiently flexible to be interpreted differently by different communities, so they can be locally useful without requiring complete consensus (Star and Griesemer 1989). Regarding shared identity, we argue that smart products have a unique identity that manifests in their hardware and software components. This shared identify serves as a common reference point (Becker et al. 2013b) during interactions between service consumers and service providers. As for local usefulness, we argue that smart products can be interpreted differently by service consumers and service providers, subject to the value propositions that they offer. While service consumers are primarily interested in creating value-in-use from using a smart product, service providers are interested in optimizing the product's operation and condition, in controlling and manipulating the product remotely, and learning from analyzing the data the product collects. For instance,

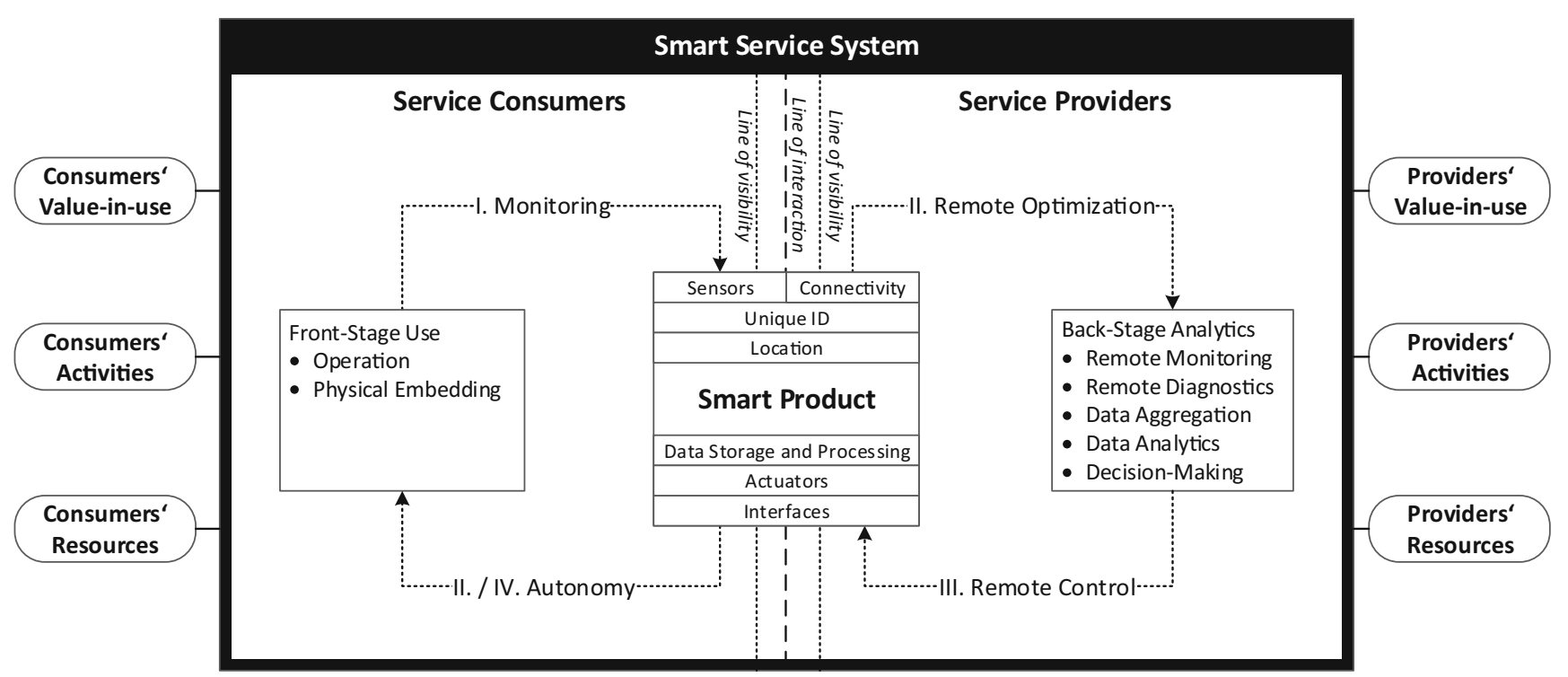

Fig. 1 Conceptualization of a smart service system based on using smart products as boundary objects 
the smart-energy infrastructure components Energy Solutions, Inc., provides are used by its customers to source electricity, while Energy Solutions, Inc. uses them primarily to detect patterns in energy consumption in order to optimize electricity distribution and tailor pricing models. Thus, although the two actors perceive and use the smart product in different ways, it acts as a reference point for their service interactions and is useful for both, even though each extracts different utility from it. The shared identity and local usefulness of smart products as boundary objects, as elicited from the five cases, are summarized in Table 2. Besides shared identity and local usefulness, boundary objects are characterized by modularity (i.e., different elements of a boundary object serve different actors), abstraction (i.e., a boundary object abstracts from details that are relevant only to certain actors), accommodation (i.e., different actors can use the information a boundary object conveys for different purposes), and standardization (i.e., the information a boundary object provides conforms to a certain level of standardization so that it is interpretable by different actors) (Star and Griesemer 1989; Pawlowski and Robey 2004; Wenger 1998). For example, a smart car consists of thousands of different sub-systems with distinct purposes (e.g., condition monitoring, navigation, entertainment), delivering data at different levels of granularity to different users (e.g., current speed to the driver versus a complete history of trips with GPS coordinates and detailed engine condition to the manufacturer). The data provided are used for different purposes by different stakeholders (e.g., positioning data for navigating versus engine conditions for predictive maintenance), and the data adhere to international standards to ensure data exchange with other cars, traffic infrastructure, and different manufacturers and service providers. (See, e.g., https://www. w3.org/community/autowebplatform/.) In summary, in their role as boundary objects, smart products are mechanisms that overcome the "segmentation of the institutional order," which
Table 2 Shared identity and local usefulness of smart products as boundary objects, as identified in the analyzed cases

\begin{tabular}{|c|c|c|}
\hline Case and smart products & Shared identity & Local usefulness \\
\hline $\begin{array}{l}\text { Metallurgic Plants, Inc.: } \\
\text { Automated manufacturing } \\
\text { technology for steel mills }\end{array}$ & $\begin{array}{l}\text { Shared view on the use of } \\
\text { machines for metal processing, } \\
\text { to compare manufacturing } \\
\text { processes with pre-engineered } \\
\text { blueprints. }\end{array}$ & $\begin{array}{l}\text { For service consumers: Metal } \\
\text { processing, quality assurance. } \\
\text { For service providers: } \\
\text { Monitoring of manufacturing } \\
\text { processes, predictive } \\
\text { maintenance, and quality } \\
\text { assurance. }\end{array}$ \\
\hline $\begin{array}{l}\text { Energy Solutions, Inc.: } \\
\text { Smart energy meters and energy } \\
\text { grid infrastructure }\end{array}$ & $\begin{array}{l}\text { Shared view of energy routing } \\
\text { through the grid and of energy } \\
\text { consumption in buildings. }\end{array}$ & $\begin{array}{l}\text { For service consumers: Sourcing of } \\
\text { electricity, monitoring and } \\
\text { optimizing energy consumption. } \\
\text { For service providers: Patterns } \\
\text { in energy consumption, } \\
\text { optimized electricity } \\
\text { distribution, tailored pricing } \\
\text { models. }\end{array}$ \\
\hline $\begin{array}{l}\text { Automobile, Inc.: } \\
\text { Smart car }\end{array}$ & $\begin{array}{l}\text { Shared view of user, vehicle, } \\
\text { and traffic data. }\end{array}$ & $\begin{array}{l}\text { For service consumers: Efficient } \\
\text { and convenient driving, parking, } \\
\text { and maintenance; car sharing. } \\
\text { For service providers: Predictive } \\
\text { maintenance, autonomous } \\
\text { driving, user-specific profiles, } \\
\text { insurance services. }\end{array}$ \\
\hline $\begin{array}{l}\text { Automobile, Inc.: } \\
\text { Automated manufacturing } \\
\text { technology }\end{array}$ & $\begin{array}{l}\text { Shared view of data on } \\
\text { manufacturing processes, use, } \\
\text { and conditions. }\end{array}$ & $\begin{array}{l}\text { For service consumers: } \\
\text { Automobile manufacturing, } \\
\text { quality assurance. For service } \\
\text { providers: Secondary use of data } \\
\text { for transparent factories, } \\
\text { predictive maintenance, and } \\
\text { quality assurance. }\end{array}$ \\
\hline $\begin{array}{l}\text { Industrial Solutions, Inc.: } \\
\text { Automated manufacturing } \\
\text { technology }\end{array}$ & $\begin{array}{l}\text { Shared view of the use and } \\
\text { condition of the machines, and } \\
\text { the machine's physical context } \\
\text { in a } \\
\text { smart factory. }\end{array}$ & $\begin{array}{l}\text { For service consumers: Use smart } \\
\text { products for industrial } \\
\text { manufacturing. For service } \\
\text { providers: Preventive } \\
\text { maintenance, automated } \\
\text { production, power-by-the-hour } \\
\text { business models. }\end{array}$ \\
\hline
\end{tabular}


disaggregates knowledge because of the division of labor and a focus on distinct core competencies (Berger and Luckmann 1966, p. 82).

We conceptualize the capabilities of smart products based on the four capabilities of smart, connected products Porter and Heppelmann (2014)proposed: monitoring, control, optimization, and autonomy. While these properties were introduced with a focus on using a product in the front stage of a service system, we relax the assumption that each property "builds on the preceding one" (p. 8), in order to assign them either to the front stage or the back stage of a smart service system. All four core capabilities can be illustrated using examples from our cases. For example, at Metallurgic Plants, Inc. dozens of sensors monitor data about vibrations, temperatures, emissions, and production velocity in order to detect early warning signals of potential process deviations, A central human machineoperator observes these data and can control the machine's operations. Automobile, Inc.'s smart production lines also monitor data continously. Besides monitoring and controlling individual devices, data, about energy consumption (for example) from various locations is aggregated and benchmarked against each other to optimize comparable plants' energy efficiency. Moreover, Energy Solutions, Inc. embeds machine-learning algorithms into their products in order to enable devices to make autonomous decisions, as the interviewee explained: "If I get real-time data, but cannot make real-time decisions, the whole thing does not make much sense. Hence, the complete [energy distribution] process needs to be automated. The network operator will, at most, be informed about the next steps a local smart device will execute. Maybe he can intervene, but the complete control loop is automated."

In the front stage, smart products are used to create and capture value-in-use (Vargo and Lusch 2004a, 2008a), such as by manufactured products in a smart factory or by smart cars that assist the driver in efficiently and conveniently making his or her way from point $\mathrm{A}$ to point $\mathrm{B}$ and finding parking spaces. In line with Wünderlich et al. (2012), we propose that using a smart product is essentially a self-service carried out by a customer with little or no intervention from the service provider. Since all companies are resource integrators (Vargo and Lusch 2008a, 2004a), a smart product is networked with other resources in its physical environment in order to create value-in-use. For instance, the interviewee from Industrial Solutions, Inc. explains how a machine is embedded into a smart factory and integrated with other machines, raw materials, and workers "In the future the planning process will change completely, so that when you connect a new smart device to some larger facility, it just runs, without long integration. And if I want to make changes, I just perform them, and the complete facility and production processes adapt themselves."

By using its built-in features, a smart device can monitor itself and its environment and collect three types of data: Usage data refers to documenting how a smart product is used, (e.g. a history of activities performed along with their duration and intensity). Context data refers to data about the products physical and virtual environment (Abowd et al. 1999), and is either collected via the built-in sensors of a context-aware smart product or originated from other devices in the proximity of a smart product (Abowd et al. 1999). Finally, condition data refers to data on the status and health of the product that can, for instance, provide information about maintenance activities. In all of the cases we analysed, we found evidence of the importance of collecting data through smart products. While most informants agreed that data collection through connected devices is not novel, they emphasized that the scope, granularity, and velocity of data has improved makedly in the last years, thereby enabling new possibilities for action. For example, the manufacturing informant at Automobile, Inc. argued that "because of the low quality of sensors in the past, it was not worthwhile to analyze sensor measurements. Today, [with data quality improved by an order of magnitude] many things start to pay off." Similarly, the interviewee from Industrial Solution, Inc. stated, "I think that the KPIs will not change much; data about time, costs, and quality might get a little more transparent, a little more fine-grained, but they would not change very much. What will change is that I can drill down to data about single machines. [...] In the future, we might be able to perform very detailed analyses to identify which machine with which parameters was involved in manufacturing a product.” Automobile, Inc.'s smart car informant emphasized the ultimate goal "to move beyond the car and really look at the user," which is sought today by gaining context from a smart phone connected to the car. In the near future, biometric sensors are likely to be used to create a user context. The interviewee from Metallurgic Plants, Inc. even sees a future in which data collected through smart products can be marketed to customers: "Detailed data on the manufacturing process is recorded in a steel mill and made available to inform downstream manufacturing processes. [...] Many customers of our customers, particularly those in the automobile industry, want to have seamless quality data on the manufacturing processes. These data should be supplied with the product."

With its actuators and its built-in functionality for data storage and processing, smart products can adapt autonomously to changes in their environments, condition, and use. These functions - referred to as self-* concepts - include, self-configuration, self-optimization, self-healing, and self-protection (Psaier and Dustdar 2011; Jeffrey and David 2003). Another distinctive property of a smart product is that it can connect to other actors outside its immediate physical context to provide 
usage data, contex data and condition data. In the back stage, these data can be retrieved remotely to monitor, diagnose, and optimize the product as a service from the product's provider (Wünderlich et al. 2012), since it involves little or no activities from the service consumer. Insights can be derived from the data that is obtained from one product, or from a complete installed base of many products. Such back-stage analysis capabilities differ substantially from the self-* capabilities that are embedded in a smart product itself, which are restricted to local data and are constrained by smart products' often limited information-processing capabilities. Building on the results of data analysis, a smart product can be controlled remotely, reconfigured, or even used as a platform to provide additional value to an ecosystem of third-party service providers (Papert and Pflaum 2017). Therefore, smart products can be viewed as service platforms that provide various value propositions that can be accepted in the service system's front stage.

\section{Discussion}

Our conceptualization of smart service and smart service systems synthesizes and complements earlier thinking by focusing on the inner workings of how value-in-use can be derived from using a smart product as a boundary object between a service's consumers and its provider. With this conceptualization, we contribute to integrating disparate streams of research. On the one hand, the service science literature has focused on the co-creation of value in service systems (Maglio and Spohrer 2008; Maglio et al. 2009; Vargo and Lusch 2004a, b, 2008a, b) without explicitly building on the properties of smart products or their role in service systems. On the other hand, the literature on smart objects in an Internet of Things (Allmendinger and Lombreglia 2005; Acatech 2011, 2015; EPoSS 2008; Estrin et al. 2002; Perera et al. 2014; Satyanarayanan 2001) has focused on the technical aspects of connecting objects with each other and with information systems, without recognizing the implications for provider-customer interactions and value co-creation. In this sense, our paper takes a boundary-spanning role by bridging the gap between previously unconnected communities in research and practice (Wenger 1998).

We argue that the emergent embedding of smart products into service systems will have transformational impacts on service systems in practice, and on theory in service science. To an extent, these transformations are due to new ways in which resources and activities can be networked in smart service systems and, ultimately, to how value is co-created and captured in these systems. Against the backdrop of the proposed conceptualization of smart service systems, we expect these transformations to have implications for the collection and analysis of detailed field evidence on the customer's service system, for remote service provision in ecosystems of service providers and service customers, and for autonomous adaptations of a service system through smart products' self-* properties.

The first implication that the embedding of smart products into service systems has for service systems in practice and theory has to do with collecting and analyzing detailed field evidence. Our interviews revealed that smart products' capabilities make new types and qualities of data available. With these data, hidden activities and resources on the consumer side become increasingly visible and accessible to the provider side. This field evidence, offers new insights into how customers use products and service and why certain events (e.g., breakdowns) occur that have implications for how service process analysis is done. Currently, a strong emphasis of data analysis is on periodic offline monitoring, but first steps have already been taken toward online analyses of service processes (vom Brocke et al. 2014), and the next steps are likely to extend process analyses towards real-time and predictive analytics (Shmueli and Koppius 2011; Breuker et al. 2016). From a theoretical viewpoint, we argue that the emergence of smart products moves or even removes the 'line of visibility' that usually separates consumers from providers during episodes of value co-creation.

The second implication has to do with the remote control, re-configuration, updating, and personalization of smart products. Using smart products as platforms for offering additional services facilitates networking activities and resources beyond the one-directional analysis of field data. We argue that closing the loop of monitoring and reacting to field data from a smart product impacts many of the taken-for-granted concepts on which co-creation in service systems is based. In particular, we conclude that using smart products as boundary objects at the interface of service consumers and service providers alters the "line of interaction" between them. In particular, this use of smart products leads to technology-mediated interactions, continuous interactions, and routinized interactions:

- Technology-mediated interactions: While key concepts of the service literature have been investigated in settings in which interactions between service customers and service providers are mediated by technology (Wünderlich et al. 2012; Froehle and Roth 2004), smart service systems require that the concept of customer interaction be updated. In smart service systems, the primary objective of technology is not restricted to mediating interactions between humans (even less so in the sense of telecommunication technology that is used by humans and enabled by "screens" (Froehle and Roth 2004)), nor is it to enable customer self-service alone. In smart service systems, smart products can be used to connect smart products and information systems on either side, so interactions that are mediated by smart products include 
exchanging data in a machine-readable format, such as the transmission of data and events to the information systems service providers operate.

- Continuous service interactions: The remote monitoring, optimization, and control of smart products enables the day-to-day activities of service consumers and service providers to be networked based on continuous interactions and a continuous exchange of data. This approach differs substantially from service interactions as isolated episodes (Froehle and Roth 2004) or service incidents (Bitner et al. 1990), where customers interact with service providers for a limited time, often in non-routine recovery events (Parasuraman et al. 2005). Therefore, we submit that, in smart service systems, the duration appropriateness (Froehle and Roth 2004) of the interaction is different and interactions can be continuous, focusing on the orderly operation of a smart product. These continuous service interactions are often a prerequisite for as-aservice business models since these interactions enable providers to track how customers use their products so providers can avoid the adverse effects of information asymmetries (Mishra et al. 1998; Williamson 1979, 1985).

- Routinized interactions: Continuous service interactions that are based on a continuous exchange of data provide new opportunities for routinizing interactions in service systems (Becker et al. 2013a). Routinizing interactions can help to coordinate and control activities, legitimate the actions performed by the actors involved, economize on resources, reduce uncertainty, increase stability, and store information about the interactions (Becker 2004) in a smart service system.

The third implication has to do with the self-* capabilities of smart products, which enable autonomous adaptations of smart products in reaction to the data obtained from the product. Therefore, it is likely that smart products will offer more individualized value propositions to customers - a key part of the concept of co-creation. On the one hand, creating personalized service experiences for customer seems desirable because they provide sequential variety in service processes (Pentland 2003) and might offer value propositions that are tailored to the needs, wants, and demands of individual customers. On the other hand, these adaptations can be considered as deviations from a pre-engineered service blueprint that is often established to provide service of uniform quality. Deviation caused by autonomous adaptations is likely to differ conceptually from deviation caused by human decisions, since smart products are data processing machines that are unaware of organizational values and culture, that often govern human in behavior service systems. Similar phenomena have been described as deviations of the performative aspects (i.e., identifiable enactments of an activity) from the ostensive aspects (i.e., the blueprint of the process as described in a process model) of organizational routines (Feldman and Pentland 2003; Pentland and Feldman 2008; Beverungen 2014). Therefore, the further proliferation of smart service systems necessitates analyses and reconceptualization of concepts like service experience and service quality.

\section{Conclusion}

We conceptualized smart service systems as being built on using smart products as boundary objects that enable service consumers and service providers to network their resources and activities for mutual advantage. The proposed conceptual framework extends earlier thinking about what smart service systems are. We developed our framework based on various streams of technical and managerial literature and in-depth interviews with informants from five industrial service systems that apply smart products as boundary objects. While smart products offer a shared identity on which the actors in a smart service system can rely, service consumers and service providers enact smart products for to be locally useful. Service consumers use, network, monitor, and autonomously adapt smart products in the service system's front stage, while service providers aggregate and analyze longitudinal data to optimize and control remotely how their installed base of smart products is used in the field. These properties of smart service systems challenge foundational concepts on which the service science field has been built. In particular, we discussed why we expect interactions in smart service systems to become increasingly technology-mediated, continuous, and routinized.

The limitations of our research include the impossibility of statistical generalizing from the cases we analyzed since our selection of companies was not made based on statistical sampling. Since the outcomes of the interviews depend heavily on the interaction between the interviewers and the interviewee, other researchers might have obtained different data from the same companies or might have reached other conclusions after coding the data. While these limitations are inherent in our qualitative research design, the design enabled us to illustrate how the advent of smart products can transform (and already has transformed) service systems.

Other researchers can build on our results to study smart service systems in other industry sectors based on theoretical sampling. While the cases we investigated for the purpose of this paper all operate in a business-to-business context and focus on smart products with comparatively elaborated computational capabilities, we expect useful results from triangulating and extending the results to smart service systems that use simple appliances to provide smart service for smart living or smart healthcare in business-to-consumer contexts. For instance, our 
framework of smart service systems could also be used to analyze dynamic interactions between stakeholders (Solaimani et al. 2013). Because of the limited computational power of smart devices, we expect that, in business-to-consumer cases, more functionality is transferred from the consumer (front stage) to the service provider (back stage), who then use the field data to offer complementary service. For instance, wearable activity trackers like the wristbands offered by Fitbit and Jawbone, supply data not only to their user but also to the provider companies, who then design and offer analytics-driven services on top of these data, often in collaboration with other service providers, such as physicians and health insurance companies (Davenport and Lucker 2015). Examples of such value-added services range from reminding users about their fitness goals and motivating them through virtual running competitions on Facebook to discounted health insurance plans for especially active customers.

Open Access This article is distributed under the terms of the Creative Commons Attribution 4.0 International License (http:// creativecommons.org/licenses/by/4.0/), which permits unrestricted use, distribution, and reproduction in any medium, provided you give appropriate credit to the original author(s) and the source, provide a link to the Creative Commons license, and indicate if changes were made.

\section{References}

Aarts, E., Harwig, R., \& Schuurmans, M. (2002). Ambient Intelligence. In P. J. Denning (Ed.), The invisible future - the seamless integration of technology in everyday life (pp. 235-250). Columbus: McGrawHill.

Abowd, G. D., Dey, A. K., Brown, P. J., Davies, N., Smith, M. E., \& Steggles, P. (1999). Towards a better understanding of context and context-awareness. In H.-W. Gellersen (Ed.), Handheld and ubiquitous computing, lecture notes on computer science (LNCS) 1707 (pp. 304-307). Berlin: Springer. https://doi.org/10.1007/3-54048157-5.

Acatech. (2011). Cyber-physical systems: driving force for innovation in mobility, health, energy and production. Germany: Munich http:// www.acatech.de/fileadmin/user_upload/Baumstruktur_nach_ Website/Acatech/root/de/Publikationen/Stellungnahmen/acatech_ POSITION

Acatech. (2015). Smart service welt: recommendations for the strategic initiative web-based services for businesses (short version). Berlin: Germany http://www.acatech.de/fileadmin/user upload/ Baumstruktur_nach_Website/Acatech/root/de/Projekte/Laufende Projekte/Smart Service.

Allmendinger, G., \& Lombreglia, R. (2005). Four strategies for the age of smart services. Harvard Business Review, 83(10), 131-145. https:// doi.org/10.1225/R0510J.

Atzori, L., Iera, A., \& Morabito, G. (2010). The internet of things: a survey. Computer Networks, 54(15), 2787-2805. https://doi.org/ 10.1016/j.comnet.2010.05.010.

Barile, S., \& Polese, F. (2010). Smart service systems and viable service systems: applying systems theory to service science. Service Science, 2(1-2), 21-40. https://doi.org/10.1287/serv.2.1_2.21.

Becker, M. C. (2004). Organizational routines: a review of the literature. Industrial and Corporate Change, 13(4), 643-677 http://icc. oupjournals.org/cgi/doi/10.1093/icc/dth026.
Becker, J., Beverungen, D., Knackstedt, R., Matzner, M., Müller, O., \& Pöppelbuß, J. (2013). Designing interaction routines in service networks: a modularity and social construction-based approach. Scandinavian Journal of Information Systems, 25(1), 17-48.

Becker, J., Beverungen, D., Knackstedt, R., Matzner, M., Müller, O., \& Pöppelbuß, J. (2013b). Bridging the gap between manufacturing and service through IT-based boundary objects. IEEE Transactions on Engineering Management, 60(3), 468-482. https://doi.org/10.1109/ TEM.2012.2214770.

Berger, P. L., \& Luckmann, T. (1966). The social construction of reality: A treatise in the sociology of knowledge. Garden City: Doubleday.

Beverungen, D. (2014). Exploring the interplay of the design and emergence of business processes as organizational routines. Business \& Information Systems Engineering, 6(4), 191-202. https://doi.org/10. 1007/s12599-014-0335-3.

Bitner, M. J., Booms, B. H., \& Stanfield Tetreault, M. (1990). The service encounter: diagnosing favorable and unfavorable incidents. Journal of Marketing, 54(1), 71-84. https://doi.org/10.2307/1252174.

Breuker, D., Matzner, M., Delfmann, P., \& Becker, J. (2016). Comprehensible predictive models for business processes. MIS Quarterly, 40(4), 1009-1034.

Carlile, P. R. (2002). A pragmatic view of knowledge and boundaries: boundary objects in new product development. Organization Science, 13(4), 442-455 JSTOR. doi:https://doi.org/10.1287/orsc. 13.4.442.2953.

Davenport, T. H., \& Lucker, J. (2015). Running on data. Deloitte Review, 16, 5-15 http://d2mtr37y39tpbu.cloudfront.net/wp-content/uploads/ 2015/01/DR16_running_on_data.pdf.

Demirkan, H., Bess, C., Spohrer, J. C., Rayes, A., Allan, D., \& Moghaddam, Y. (2015a). Innovations with smart service systems: analytics, big data, cognitive assistance, and the internet of everything. Communications of the Association for Information Systems, 37,35 .

Demirkan, H., Spohrer, J. C., \& Badinelli, R. (2015b). Introduction to the smart service systems: Analytics, cognition and innovation minitrack. In Proceedings of the 48 Hawaii international conference on systems sciences (HICSS) (p. 1442). https://doi.org/10.1109/ HICSS.2015.175.

EPoSS. (2008). Internet of things in 2020: A roadmap for the future. Rfid working group of the European technology platform on smart systems integration (Eposs). http://www.smart-systems-integration.org/ public/documents/publications/Internet-of-Things_in_2020_ECEPoSS Workshop_Report_2008_v3.pdf.

Estrin, D., Culler, D., Pister, K., \& Sukhatme, G. (2002). Connecting the physical world with pervasive networks. IEEE Pervasive Computing, 1(1), 59-69. https://doi.org/10.1109/MPRV.2002. 993145.

Feldman, M. S., \& Pentland, B. T. (2003). Reconceptualizing organizational routines as a source of flexibility and change. Administrative Science Quarterly, 48(1), 94-118. https://doi.org/10.2307/3556620.

Finnegan, M. (2013). Boeing 787s to create half a terabyte of data per flight, says Virgin Atlantic. Computerworld UK. http://www. computerworlduk.com/news/data/boeing-787s-create-half-terabyteof-data-per-flight-says-virgin-atlantic-3433595/.

Froehle, C. M., \& Roth, A. V. (2004). New measurement scales for evaluating perceptions of the technology-mediated customer service experience. Journal of Operations Management, 22(1), 1-21. https://doi.org/10.1016/j.jom.2003.12.004.

Gretzel, U., Sigala, M., Xiang, Z., \& Koo, C. (2015). Smart tourism: foundations and developments. Electronic Markets 25(3), 179188. https://doi.org/10.1007/s12525-015-0196-8.

Jeffrey, O., \& David, M. (2003). The vision of autonomic computing. IEEE Computer 36(1), 41-50. https://doi.org/10.1109/MC.2003. 1160055 . 
Kingman-Brundage, J. (1989). The ABCs of service system blueprinting. In M. J. Bitner \& L. A. Crosby (Eds.), Designing a winning service strategy (pp. 30-33). Chicago: American Marketing Association.

Lovelock, C., \& Gummesson, E. (2004). Whither services marketing?: In search of a new paradigm and fresh perspectives. Journal of Service Research, 7(1), 20-41. https://doi.org/10.1177/1094670504266131.

Lusch, R. F., \& Vargo, S. L. (2006). The service-dominant logic of marketing: Dialog, debate, and directions. New York: Sharpe.

Lusch, R. F., Vargo, S. L., \& Wessels, G. (2008). Toward a conceptual Foundation for Service Science: contributions from servicedominant logic. IBM Systems Journal, 47(1), 5-14. https://doi.org/ 10.1147/sj.471.0005.

Maglio, P. P., \& Spohrer, J. (2008). Fundamentals of service science. Journal of the Academy of Marketing Science, 36(1), 18-20. https://doi.org/10.1007/s11747-007-0058-9.

Maglio, P. P., Srinivasan, S., Kreulen, J. T., \& Spohrer, J. (2006). Service systems, service scientists, SSME, and innovation. Communications of the ACM, 49(7), 81-85. https://doi.org/10.1145/1139922.1139955.

Maglio, P. P., Vargo, S. L., Caswell, N., \& Spohrer, J. (2009). The service system is the basic abstraction of service science. Information Systems and e-Business Management, 7(4), 395-406. https://doi. org/10.1007/s10257-008-0105-1.

Massink, M., Michael H., \& D. Latella. (2010). Scalable analysis of collective behaviour in smart service systems. In: Proceedings of the 2010 ACM symposium on applied computing, pp. 1173-1180.

Mishra, D. P., Heide, J. B., \& Cort, S. G. (1998). Information asymmetry and levels of agency relationships. Journal of Marketing Research, 35(3), 277-295. https://doi.org/10.2307/3152028.

National Science Foundation. (2014). Partnerships for innovation: Building innovation capacity (PFI:BIC). Program Solicitation NSF14-610: 5. https://www.nsf.gov/pubs/2014/nsf14610/ nsf14610.pdf.

Ostrom, A. L., Parasuraman, A., Bowen, D. E., Patricio, L., \& Voss, C. A. (2015). Service research priorities in a rapidly changing context. Journal of Service Research, 18(2), 127-159. https://doi.org/10. $1177 / 1094670515576315$.

Papert, M., \& Pflaum, A. (2017). Development of an ecosystem model for the realization of internet of things (IoT) services in supply chain management. Electronic Markets, 27(2), 175-189. https://doi.org/ 10.1007/s12525-017-0251-8.

Parasuraman, A., Zeithaml, V. A., \& Malhotra, A. (2005). E-S-QUAL: A multiple-item scale for assessing electronic service quality. Journal of Service Research, 7(3), 213-233. https://doi.org/10.1177/ 1094670504271156

Pawlowski, S. D., \& Robey, D. (2004). Bridging user organizations: knowledge brokering and the work of information technology professionals. MIS Quarterly, 28(4), 645-672.

Pentland, B. T. (2003). Conceptualizing and measuring variety in the execution of organizational work processes. Management Science, 49(7), 857-870. https://doi.org/10.1287/mnsc.49.7.857.16382.

Pentland, B. T., \& Feldman, M. S. (2008). Designing routines: on the folly of designing artifacts, while hoping for patterns of action. Information and Organization, 18(4), 235-250. https://doi.org/10. 1016/j.infoandorg.2008.08.001.

Perera, C., Zaslavsky, A., Christen, P., \& Georgakopoulos, D. (2014). Context aware computing for the internet of things: a survey. IEEE Communications Surveys and Tutorials, 16(1), 414-454. https://doi. org/10.1109/SURV.2013.042313.00197.

Porter, M. J., \& Heppelmann, J. E. (2014). How smart, connected products are transforming competition. Harvard Business Review, (November).

Psaier, H., \& Dustdar, S. (2011). A survey on self-healing systems: approaches and systems. Computing, 91(1), 43-73. https://doi.org/10. 1007/s00607-010-0107-y.
Saldaña, J. (2009). The coding manual for qualitative researchers. London: Sage.

Satyanarayanan, M. (2001). Pervasive computing: vision and challenges. IEEE Personal Communications, 8(4), 10-17. https://doi.org/10. 1109/98.943998.

Shmueli, G., \& Koppius, O. R. (2011). Predictive analytics in information systems in research. Management Information Systems Quarterly2, 35(3), 553-572.

Shostack, G. L. (1982). How to design a service. European Journal of Marketing, 16(1), 49-63. https://doi.org/10.1108/ EUM0000000004799.

Solaimani, S., Guldemond, N., \& Bouwman, H. (2013). Dynamic stakeholder interaction analysis: innovative smart living design cases. Electronic Markets, 23(4), 317-328. https://doi.org/10.1007/ s12525-013-0143-5.

Star, S. L. (2010). This is not a boundary object: reflections on the origin of a concept. Science, Technology \& Human Values, 35(5), 601617. https://doi.org/10.1177/0162243910377624.

Star, S. L., \& Griesemer, J. R. (1989). Institutional ecology,translations' and boundary objects: amateurs and professionals in Berkeley's museum of vertebrate zoology, 1907-39. Social Studies of Science, 19(3), 387-420. https://doi.org/10.1177/030631289019003001.

Vargo, S. L., \& Lusch, R. F. (2004a). The four service marketing myths: remnants of a goods-based, manufacturing model. Journal of Service Research, 6(4), 324-335. https://doi.org/10.1177/ 1094670503262946.

Vargo, S. L., \& Lusch, R. F. (2004b). Evolving to a new dominant logic for marketing. Journal of Marketing, 68(1), 1-17. https://doi.org/10. 1509/jmkg.68.1.1.24036.

Vargo, S. L., \& Lusch, R. F. (2008a). Why 'service'? Journal of the Academy of Marketing Science, 36(1), 25-38. https://doi.org/10. 1007/s11747-007-0068-7.

Vargo, S. L., \& Lusch, R. F. (2008b). Service-dominant logic: continuing the evolution. Journal of the Academy of Marketing Science, 36(1), 1-10. https://doi.org/10.1007/s11747-007-0069-6.

Vargo, S. L., \& Lusch, R. F. (2016). Institutions and axioms: an extension and update of service-dominant logic. Journal of the Academy of Marketing Science, 44, 5-23. https://doi.org/10.1007/s11747-015-0456-3.

Vargo, S. L., Lusch, R. F., \& Archpru, A. (2010). Advancing service science with service-dominant logic - clarifications and conceptual development. In P. P. Maglio, C. A. Kieliszewski, \& J. C. Spohrer (Eds.), Handbook of service science: Research and innovations in the service economy (pp. 133-156). Berlin: Springer.

vom Brocke, J., Debortoli, S., Müller, O., \& Reuter, N. (2014). How inmemory technology can create business value: insights from the Hilti case. CAIS, 34, 7. http://aisel.aisnet.org/cais/vol34/iss1/7

Weiser, M. (1991). The computer for the 21st century. Scientific American, 265(3), 66-75. https://doi.org/10.1109/MPRV.2002.993141.

Weiser, M. (1993). Hot topics-ubiquitous computing. IEEE Computer, 26(10), 71-72. https://doi.org/10.1109/2.237456.

Wenger, E. (1998). Communities of practice. Learning, meaning, and identity. Cambridge: Cambride University Press.

Williamson, O. E. (1979). Transaction-cost economics: the governance of contractual relations. Journal of Law and Economics, 22(2), 233261. https://doi.org/10.1086/466942.

Williamson, O. E. (1985). The economic intstitutions of capitalism. New York City: The Free Press.

Wortmann, F., \& Flüchter, K. (2015). Internet of things. Business \& Information Systems Engineering, 57(3), 1-4. https://doi.org/10. 1007/s12599-015-0383-3.

Wünderlich, N. V., Wangenheim, F. V., \& Bitner, M. J. (2012). High tech and high touch: a framework for understanding user attitudes and behaviors related to smart interactive services. Journal of Service Research, 16(1), 3-20. https://doi.org/10.1177/1094670512448413. 